\title{
Practice patterns of neurology in India: Fewer hands, more work
}

\author{
S. V. Khadilkar, S. Wagh \\ Department of Neurology, Grant Medical College and Sir JJ Group of Hospitals, Mumbai, India
}

Background: India is a populous country housing over a billion people. Neurology as a specialty is being practiced in India for over 50 years but the number of physicians devoted to fulltime neurology is limited. This fact coupled with the privatized healthcare system and limited infrastructure has led to situations different from the more developed healthcare systems. Aim: To study the practice patterns of neurology in India. Setting and Design: Questionnaire-based study. Materials and Methods: Questionnaire was sent to 250 members of the Indian Academy of Neurology [sample size approximately $25 \%$ ] using random number table. The responses were tabulated and analyzed. Results and Conclusions: The neurology group is small and hence is exposed to a large workload. The average number of patients seen daily by Indian neurologists is three to four times those seen by the United States and United Kingdom neurologists. Neurologists based at district places are more likely to see direct patients; whereas metropolitan neurologists see more referrals. Investigative facilities are available to neurologists but affordability is a concern. Clinical work leaves less time for academic and research activities, which the consultants are keen to participate in. In the privatized health system of India, emergency work constitutes a difficult area to cope with. The concept of single specialty group practice is welcomed by the majority with the idea of streamlining their work and life. These factors highlight an urgent need for increasing the neurology work force and argue for further involvement of primary physicians and internists in neurological care in India.

Key words: Neurology, practice, India

India is a populous country, being home to one billion people. Even though the science of neurology took roots in India over half a century ago, neurology training centers and opportunities are limited and as a result, neurologists are few in number. A previous study found that in 1991, one neurologist had to cater to three million Indian people. ${ }^{[1]}$ As a result, most neurologists find themselves inundated with patient-related activities. As the patient care is largely privatized and still individualized, the system puts high demands on individual neurologists.

Over the past few years, technology has reached the far corners of India, helping modern diagnosis and patient care. In spite of technical availabilities, due to issues relating to workload, attitudes and perception, medical and social structure, scientific endeavors to study various neurological diseases clinically and in the laboratories has gained little momentum.

In this study, we analyze the working situation faced by neurologists in India, to evaluate the perceptions of practicing neurologists towards practical issues related to patient care, academic and research activities in India.

\section{Materials and Methods}

From the list of members of the Indian Academy of Neurology practicing in India, 250 were selected using random number table. A questionnaire was sent to selected neurologists (see appendix). The questionnaire focused on the time spent in various aspects of neurosciences, the workload, the ability to cope up with the workload, suggestions for improvement of the current structure of practice, and academic aspects. The responses to all the questions in the questionnaire were collected and analyzed. The percentages were calculated up to two decimals.

\section{Results}

Two hundred and ten neurologists completed the questionnaire (response rate of $84 \%$ ). Following is the analysis of these 210 responders. Out of these, 32 neurologists work at district places and others are located in large metropolitan cities. 
Distribution of work hours: Neurologists were asked as to how much time they were spending in teaching, patient care and research in a working day. It was found that $54.76 \%$ neurologists spend less than $5 \mathrm{~h}$ in teaching, only $6.19 \%$ spend more than $5 \mathrm{~h}$ and $3.81 \%$ do not do any teaching activity. $35.24 \%$ doctors did not offer a comment. In patient care, $49.52 \%$ of neurologists spend $5-10 \mathrm{~h}$, $34.28 \%$ spend $10-15 \mathrm{~h}, 8.57 \%$ spend less than $5 \mathrm{~h}$ and $2.86 \%$ spend more than $15 \mathrm{~h}$. Ten doctors did not offer a comment. In research activities, 30.95\% neurologists spend less than $1 \mathrm{~h}, 16.19 \%$ spend up to $2 \mathrm{~h}, 1.43 \%$ spend up to $3 \mathrm{~h}, 4.29 \%$ more than $3 \mathrm{~h}$ and another $4.29 \%$ don't do any research. $35.24 \%$ and $42.86 \%$ of the respondents did not comment on teaching and research activities respectively.

\section{Clinical workload}

About $50 \%$ of the respondents see 10 to 30 patients per day, $14.76 \%$ of the respondents report seeing more than 50 patients per day [Figure 1].

Most of the respondents are spending 15 to $30 \mathrm{~min}$ with the new patients but would like to spend 15 to 45 min [Figure 2]. With follow-up patients they are spending less than $15 \mathrm{~min}$ and $54.76 \%$ are happy with this.

When it came to emergencies, $84.29 \%$ felt that they could cope up with the emergency work. These $84.29 \%$ comprised two groups, one fully able to cope $(48.10 \%)$ and the other with partial difficulty (36.19\%). 7.62\% were unable to cope up with emergency work and $8.10 \%$ did not give a comment.

Referral patterns: The proportion of patients that respondents see as reference and also the proportion which they feel as genuinely needed a neurology reference was also studied. $49.52 \%$ of respondents see $20-60 \%$ of their patients as referrals and most feel that most of their references are genuine.

Access to Investigations: $70.00 \%$ of the respondents had quick access to the investigations while $24.29 \%$ did not have these facilities and the rest $5.71 \%$ did not

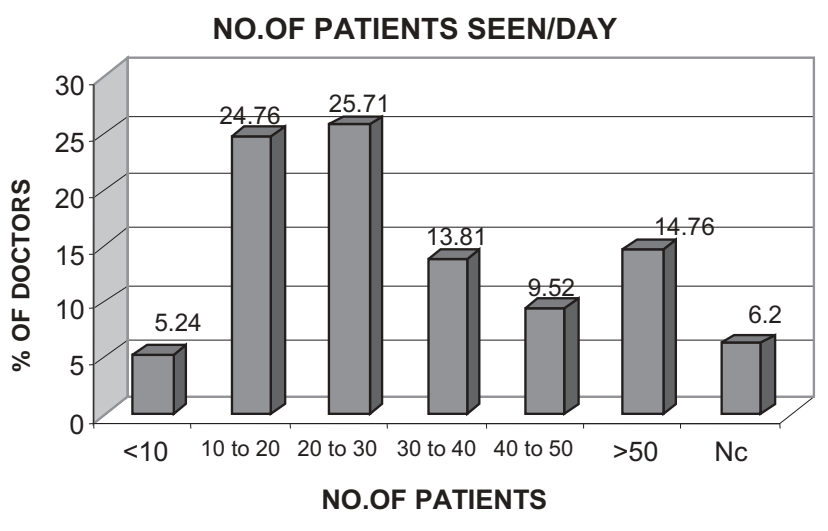

Figure 1: Average number of patients seen daily by neurologists

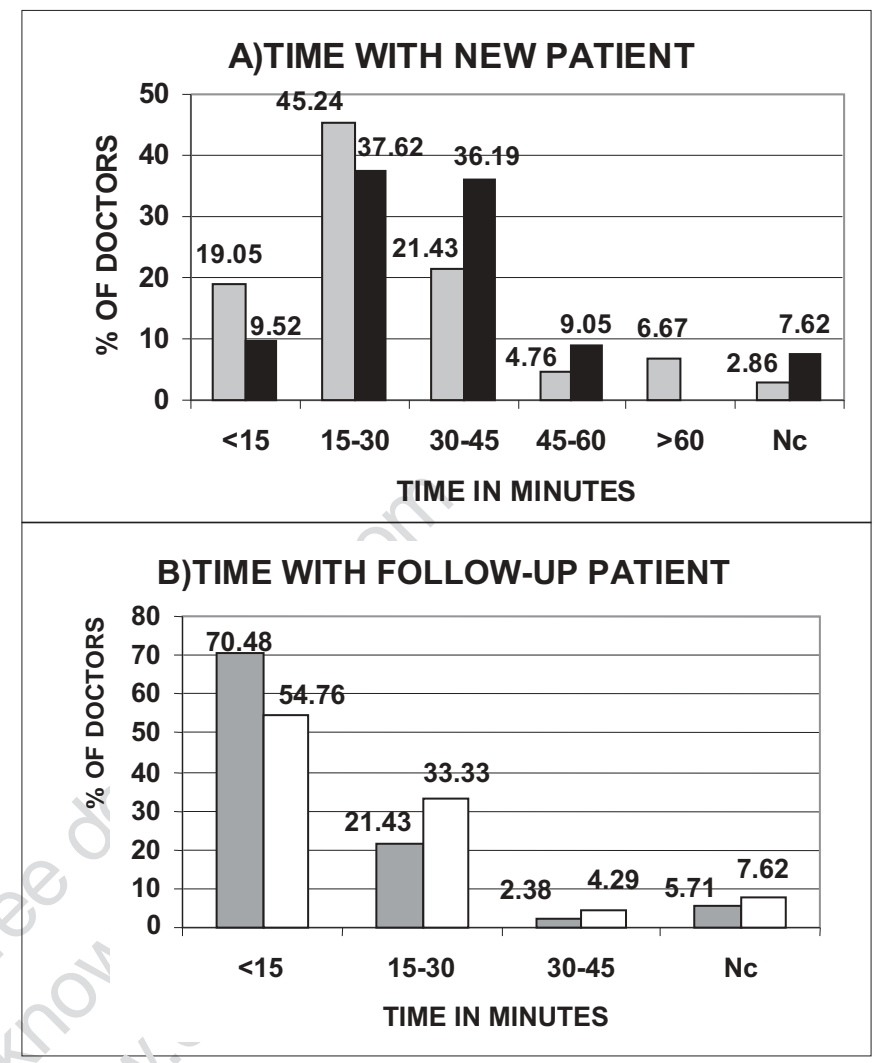

Figure 2: Time spent versus time wanted by neurologists with new (Graph-A) and follow-up patients (Graph- B)

comment. $57.62 \%$ of respondents felt that $20-60 \%$ of their patients cannot afford the investigations.

Group practice: Out of 210 respondents 111(52.86\%) responded to this question. Out of these, $94.59 \%$ felt that neurology group practice should come to India and 5.41\% were not in favor of it. The reasons given by those in favor of group practice were as shown in Table 1.

\section{Status and future of academic and research work}

One hundred and sixty-seven (79.52\%) out of 210 respondents gave suggestions for improvement of research and academics in India. They could be categorized as shown in Table 2.

Neurology training: Thirty-nine respondents had obtained either a degree or diploma outside India. Forty per cent neurologists rated their neurology training in India as excellent, $46.19 \%$ as good, $10.00 \%$ as average and $3.33 \%$ did not comment. Only one neurologist felt that neurology training was poor. After completion of their neurology training and degree course and before starting their private practice, 115 consultants had spent some time in the teaching institutions. Out of these, $45.22 \%$ had spent less than five years, $20.87 \%$ had spent between five to 10 years and the remaining $33.91 \%$ had more than 10 years of teaching experience before entering the private practice. $36.19 \%$ were extremely satisfied with the number of years spent in academic institutions after their postgraduation, $41.13 \%$ reported that they were somewhat satisfied, 3.81\% 
Table 1: Reasons for group practice

\begin{tabular}{|c|c|c|c|c|c|}
\hline $\begin{array}{l}\text { or academ } \\
\text { esearch w } \\
(4.76 \%)\end{array}$ & $\begin{array}{c}\text { To get leisure } \\
\text { time } \\
6(5.71 \%)\end{array}$ & $\begin{array}{c}\text { Bettering patient care } \\
\text { and decreasing workload } \\
41(39.05 \%)\end{array}$ & $\begin{array}{l}\text { Professional and } \\
\text { Financial security } \\
\quad 21(20.00 \%)\end{array}$ & $\begin{array}{l}\text { In favor but no } \\
\text { specific reason } \\
32(30.48 \%)\end{array}$ & $\begin{array}{c}\text { Total } \\
105(100 \%)\end{array}$ \\
\hline
\end{tabular}

Table 2: Steps needed to improve academic and research environment

\begin{tabular}{|c|c|c|c|c|c|c|}
\hline $\begin{array}{l}\text { Bettering } \\
\text { infrastructure } \\
\text { and funds }\end{array}$ & $\begin{array}{l}\text { Recruiting well } \\
\text { paid fulltime } \\
\text { research staff } \\
\text { in government } \\
\text { hospitals }\end{array}$ & $\begin{array}{l}\text { Involving private } \\
\text { agencies in } \\
\text { research }\end{array}$ & $\begin{array}{l}\text { Mandatory } \\
\text { CME attendance } \\
\text { and regular } \\
\text { registration renewal }\end{array}$ & $\begin{array}{l}\text { Promoting young } \\
\text { researchers }\end{array}$ & Nonconclusive & Total \\
\hline 58 (34.73\%) & $9(5.39 \%)$ & $11(6.59 \%)$ & $40(23.95 \%)$ & $9(5.39 \%)$ & $40(23.95 \%)$ & 167 (100\%) \\
\hline
\end{tabular}

were dissatisfied and the remaining $18.57 \%$ did not comment. $36.67 \%$ doctors felt that less than five years were sufficient before starting private practice, $13.33 \%$ opted for up to 10 years and $5.24 \%$ felt that more than 10 years were necessary to be spent in teaching institutions. A total of $44.76 \%$ consultants offered no comments.

\section{Discussion}

This questionnaire-based study highlights the current practical issues faced by Indian neurologists. The neurology group is still small and hence is exposed to a large workload. The clinical work leaves less time for academic and research activities. The emergency work constitutes a difficult area to cope with. The concept of group practice is welcomed by the majority with the idea of streamlining their work and life. The interaction between neurologists and physicians needs to be buttressed to provide adequate neurological care. These points are now discussed.

Indian neurologists are completely or almost completely involved with patient care activities. The amount of time spent in teaching was much less and further so for research activities. This working pattern is similar to that seen in the United States. ${ }^{[2,3]}$ In the present study, $52.86 \%$ of the respondents have indicated that they are involved in research activities, which is comparable to the data available from the United States where the 2001 AAN member survey has estimated the proportion of neurologists conducting neurological research to be $52.5 \% .{ }^{[4]}$ The average number of patients seen daily in the present study is very large. $23.33 \%$ of respondents see 30 to 50 patients in a given day and close to $14.76 \%$ of the respondents actually see more than 50 patients every day. This is almost three to four times the average number of patients seen by a neurologist in the United States and United Kingdom ${ }^{[2,5]}$ and is a strong reflection of the burden of clinical neurology shouldered by the comparatively few consultants in India. This reflects the average time spent with patients, first consultations often getting only $15 \mathrm{~min}$. Such magnitude of the workload raises concerns of quality control issues, which were voiced by the respondents. Approximately 50\% respondents felt that they would have liked to spend more time with new cases as well as with the follow-up cases, but could not do so because of the time constraints. This fact was more strongly registered for the first consultations. In the United Kingdom neurologists get to spend comparable time of $30 \mathrm{~min}$ with the fresh and $15 \mathrm{~min}$ with the follow-up patients. ${ }^{[6]}$ However, in the Unites States most of the neurologists have adequate time for their patients. ${ }^{[7]}$

When comparing the metropolitan and district settings, larger numbers of patients were seen by respondents working in the rural situation. This is understandable because practicing neurologists are focused in urban metropolitan cities. This trend observed in the developing countries is shared by developed countries as well. ${ }^{[7,8]}$ We analyzed the referral patterns to know whether the currently generated workload was appropriate. The percentage of referred cases and doctors' perceptions of appropriateness of the references ranged widely from under $20 \%$ to almost $100 \%$; being concentrated at 20 $60 \%$ and being smaller in district setups. It appears that in district setups in India, a larger number of patients go through the neurology consultants, often as direct patients not always requiring a neurology consultation. As opposed to this, fewer patients are seen by tertiary care consultants, most of them being genuine referrals. In the United Kingdom the appropriateness of referrals has been judged to be $76-80 \% .^{[5,9]}$

Seventy per cent of the respondents have rapid and complete access to investigations. In this regard, India is probably catching up with the developed countries where neurologists have good access to investigative facilities. ${ }^{[5]}$ But, importantly, the patients' ability to afford investigations varied from less than $20-100 \%$, being the least in rural India. Thus, the discrepancy between the availability of investigations and affordability was apparent.

India has a privatized health system and every individual neurologist works as a single independent unit or part of a small team of multi-specialty consultants. Hence consultants have to deal with their own quota of emergencies and urgent consultations. This results in unpredictable, unearthly work hours. On this background it is not unexpected that $36.19 \%$ doctors did not find themselves fully equipped for the job and $7.62 \%$ were 
extremely dissatisfied with the work pattern and expressed their inability to cope up. This fact needs to be highlighted as the current privatized working system probably puts undue pressure on the working individuals. It follows that an overwhelming majority of neurology consultants favor group practice for reduced work hours, systematic work pattern and increased time for academic and leisure activities, and availability of subspecialty expertise within the group for enhanced patient care.

The above mentioned facts emphasize the urgent need to increase the neurology workforce in India, in order to dilute the practical problems currently encountered. Considering the infrastructural limitations, this is expected to take a long time. For this time, a proportion of the neurological patients will seek advice from primary physicians and internists and hence the academic interaction between these fraternities and neurologists will need to be intensified in an effort to achieve good neurological care for Indian patients.

\section{Acknowledgements}

We thank Dr. Kasbe for his help. Special thanks are due to Dr. M Menken for his guidance and constructive comments on the manuscript We wish to thank all participants of this study.

\section{References}

1. Singhal BS, Gursahani RD, Menken M. Practice patterns in Neurology in India. Neuroepidemiology 1992;11:158-62.

2. Holloway RG, Vickrey BG, Keran CM, Lesser E, Iverson D, Larson $\mathrm{W}$, et al. US neurologists in the 1990s: Trends in practice characteristics. Neurology 1999;52:1353-61.

3. Ances BM. After neurology residency: New opportunities, new challenges. Neurology 2004;62:E12-4.

4. Swarztrauber K, Lawyer BL, members of the AAN Practice Characteristies Subcommittee. Neurologists 2000. AAN member demographic and practice characteristics. American Academy of Neurology: St. Paul; 2001.

5. Hopkins A, Menken M, DeFriese G. A record of patient encounters in neurological practice in the United Kingdom. J Neurol Neurosurg Psychiatry 1989;52:436-8.

6. Association of British Neurologists. Neurology in the United Kingdom: Towards 2000 and beyond. ABN: London; 1997. p. 1-33.

7. Ringel SP, Vickrey BG, Schembri M, Kravitz RL. Neurologists' assessment of their ability to provide high quality care. Neurology 2003;61:612-5.

8. Hooker J, Matthew, Lakshminarayan K, Souza-Lima FC, Rejdak $\mathrm{K}$, Kwiecinski H, et al. Neurology training around the world. Lancet Neurol 2003;2:572-9.

9. Wiles CM, Lindsay M. General practice referrals to a department of neurology. J R Coll Physicians Lond 1996;30:426-31.
Accepted on 20-11-2006

Source of Support: Nil, Conflict of Interest: None declared.

\section{Author Help: Choosing an appropriate category of article for faster publication}

The manuscript system (www.journalonweb.com) allows the authors to check a likely publication date for a newly submitted article. Based on number of articles in review, number of accepted articles and acceptance rate, the system estimates the likely publication date for an article submitted on a given date.

If there are too many articles in a category e.g., case report, a newly submitted case report if accepted may have to wait for a long period before publication. Hence, the author can check other categories e.g. letter to editor or images, for such paper and submit to another category of articles. 